\title{
Avaliação da concentração de proteínas e da atividade de a-galactosidases nos cotilédones e no eixo embrionário de sementes de Dalbergia nigra durante a germinação
}

Lanna Clicia CARRIJO ${ }^{1}$, Eduardo Euclydes de Lima e BORGES², Sebastião Tavares de REZENDE ${ }^{3}$ Cláudia Aparecida PONTES ${ }^{4}$, Aderlan Gomes da SILVA ${ }^{5}$, Mariana Rocha LOPES ${ }^{6}$

\section{RESUMO}

Este trabalho teve como objetivos a quantificação de proteínas e da atividade da enzima $\alpha$-galactosidase, no eixo embrionário e nos cotilédones, de sementes de Dalbergia nigra (jacarandá-da-bahia) durante a germinação. As sementes foram colocadas para embeber em água por sete dias, sendo retiradas amostras para a avaliaçáo bioquímica e cinética da enzima. A atividade da enzima $\alpha$-galactosidase aumenta com a embebição das sementes nos dois compartimentos, embora náo esteja presente no eixo embrionário de sementes secas. A diferença na atividade da enzima entre os cotilédones e o eixo embrionário foi significativa. $\mathrm{O}$ pH 5,5 foi o de máxima atividade para as enzimas de ambos os compartimentos. A temperatura que mais estimulou a atividade da enzima nos cotilédones foi $50{ }^{\circ} \mathrm{C}$ e de 50 a $60^{\circ} \mathrm{C}$ no eixo embrionário. A atividade da $\alpha$-galactosidase foi inibida por $\beta$-mercaptoetanol e cobre, em ambos os compartimentos, enquanto a lactose e o cloreto de sódio estimularam a atividade tanto nos cotilédones como no eixo embrionário. Os valores de $\mathrm{K}_{\mathrm{M}}$ para enzimas do eixo embrionário e dos cotilédones foram de 0,239 e $0,228 \mathrm{mM}$, respectivamente.

PALAVRAS-CHAVE: enzima, jacarandá-da-bahia, bioquímica.

\section{Proteins and activity of $\alpha$-galactosidases determination in cotyledons and embryonic axis of Dalbergia nigra seeds during germination}

\section{ABSTRACT}

This work aimed to quantify the protein content and the $\alpha$-galactosidase activity in the embryonic axis and in the cotyledons of Dalbergia nigra seeds during the imbibition period. The seeds were submitted to water imbibition during seven days. Biochemical and kinetic characterization of the enzyme were done from samples taken during the imbibition period. The activity of the $\alpha$-galactosidase increased in the two compartments with the soaking of the seeds, although, the enzyme activity was not detected in the embryonic axis of dry seeds. The difference in the activity of the enzyme between cotyledons and embryonic axis was significant. The $\mathrm{pH}$ of maximum activity was 5.5 for the enzyme of both compartments. In the cotyledons the higher activity of the enzyme was obtained at $50{ }^{\circ} \mathrm{C}$. In the embryonic axis the activity was higher at temperatures ranging from 50 to $60{ }^{\circ} \mathrm{C}$. The activity of the $\alpha$-galactosidase was inhibited by $\beta$-mercaptoethanol and $\mathrm{CuSO}_{4}$ in both compartments, while lactose and sodium chloride stimulated the activity in the cotyledons and in the embryonic axis. The values of $K_{M}$ for the enzymes of the embryonic axis and cotyledons were respectively 0.239 and $0.228 \mathrm{mM}$.

KEYWORDS: $\alpha$-galactosidase, seeds, Dalbergia nigra

\footnotetext{
1 Universidade Federal de Viçosa. Iannaclicia@gmail.com

2 Universidade Federal de Viçosa. elborges@ufv.br

3 Universidade Federal de Viçosa. srezende@ufv.br

${ }^{4}$ Instituto Federal de Minas Gerais. pontesac@gmail.com

5 Instituto Federal de Minas Gerais. aderlan@yahoo.com.br

6 Universidade Federal de Viçosa. mari lopes_@hotmail.com
} 


\section{INTRODUÇÃO}

O interesse no estudo da composição química das sementes tem aplicaçóes tanto nas suas propriedades nutricionais, bem como na atividade industrial. Neste caso, as enzimas têm despertado o interesse da indústria, principalmente alimentícia, por apresentar potencial para diversas aplicações biotecnológicas (Oliveira et al. 2005; Guimarães et al. 2001). Segundo Guimarães et al. (2001), a enzima $\alpha$-galactosidase tem potencial para ser utilizada na hidrólise de oligossacarídeos da série rafinósica do leite de soja.

A enzima $\alpha$-galactosidase é uma exoglicosidase que hidrolisa ligaçóes glicosídicas $\alpha-1,6$ de resíduos de galactosil em oligossacarídeos da série rafinósica e em polissacarídeos de parede celular (Fujimoto et al. 2003; Lahuta et al. 2000). Estudos da enzima $\alpha$-galactosidase têm sido realizados em sementes florestais durante a germinação (Guimarães et al. 2001; Borges et al. 2004 e 2005; Oliveira et al. 2005), em fungos (Saraswathy et al. 2007), em folhas (Chrost et al. 2007) e em raízes (Bom et al. 1998).

Os oligossacarídeos são fontes primárias de energia e substrato para a síntese de novos compostos durante a embebição e germinação das sementes (Edwards et al. 1992). A atividade enzimática, especialmente a da $\alpha$-galactosidase, aumenta nesta fase (Kontos e Spyropoulos 1996). Em sementes de Sesbania marginata, as reservas de galactomanano foram mobilizadas durante o crescimento inicial das plântulas, tendo sido observado aumento na relação manose/galactose, sugerindo que a enzima $\alpha$-galactosidase seja a hidrolase a degradar o polissacarídeo (Buckeridge e Dietrich 1996).

A espécie Dalbergia nigra, também conhecida como jacarandá-da-bahia, é nativa da Mata Atlântica, encontrada nos estados da Bahia, Espírito Santo, Rio de Janeiro, São Paulo e Minas Gerais (Lorenzi 1992). Neste contexto, os objetivos deste trabalho foram caracterizar e avaliar a atividade da enzima $\alpha$-galactosidase, no eixo embrionário e nos cotilédones, de sementes de $D$. nigra durante a germinação.

\section{MATERIAL E MÉTODOS}

Esse trabalho foi realizado no Laboratório de Análise de Sementes Florestais (LASF) do Departamento de Engenharia Florestal da Universidade Federal de Viçosa. As sementes de D. nigra foram colhidas no estádio final de maturação em Viçosa, MG, e colocadas em placas de Petri com $9 \mathrm{~cm}$ de diâmetro sobre duas folhas de papel filtro tipo Germitest, umedecidas com água destilada, mantidas em germinador com temperatura constante de $25^{\circ} \mathrm{C}$ proporcionada por quatro lâmpadas tipo fluorescente de $40 \mathrm{~W}$ cada, tipo luz do dia especial, pelo período de 10 dias. Foram utilizadas cinco repetiçóes de 20 sementes para acompanhar a porcentagem de germinação. Foram consideradas germinadas as sementes que apresentaram protrusão da radícula (Marques et al. 2002). A cada 24 horas, foram retiradas amostras e as sementes foram dissecadas em cotilédone e eixo embrionário. A extração da enzima e a determinação da sua atividade foram feitas segundo metodologia descrita por Viana (2002). Foram utilizados $100 \mathrm{mg}$ de amostra fresca para cada uma das três repetiçóes, maceradas separadamente em gral de porcelana com 1,5 mL de tampão acetato de sódio $100 \mathrm{mM} \mathrm{pH} \mathrm{5,0} \mathrm{e} \mathrm{centrifugado}$ a $24.000 \mathrm{xg}$ por 20 minutos, a $4{ }^{\circ} \mathrm{C}$. O sobrenadante foi utilizado para a determinação da atividade enzimática e da concentração de proteínas solúveis. Para a caracterização enzimática, o extrato foi preparado nas sementes com 24 horas de embebição.

O teor de proteínas foi determinado pelo método de Bradford (1976) utilizando-se curva padrão construída com albumina sérica bovina (BSA).

O ensaio-padrão para detectar a atividade da enzima foi realizado em sementes com sete dias de germinação, correspondendo àquelas que não mostravam protrusão de radícula. Utilizou-se de $700 \mu \mathrm{L}$ de tampão de extraçáo, 250 $\mu \mathrm{L} \rho$-nitrofenil- $\alpha$-D-galactopiranosídeo ( $\rho$-NPGAL) $2 \mathrm{mM}$ e $50 \mu \mathrm{L}$ de extrato enzimático. A reação foi conduzida por 15 minutos em banho termostatizado a $37^{\circ} \mathrm{C}$, sendo interrompida pela adição de $1,0 \mathrm{~mL}$ de solução de carbonato de sódio 0,5 M. A leitura da absorvância foi feita no comprimento de onda de $410 \mathrm{~nm}$. Os valores de absorbância foram transformados em $\mu \mathrm{M}$ de $\rho$-nitrofenol. Uma unidade (U) de enzima foi definida como a quantidade de enzima necessária para produzir 1,0 $\mu$ mol de $\rho$-nitrofenol por minuto.

A influência do $\mathrm{pH}$ na atividade da enzima foi avaliada na faixa de 3,0 a 8,0, com intervalos de 0,5 unidade, utilizandose tampóes McIlvaine (1921), e mantendo-se as mesmas condições do ensaio-padrão.

Os ensaios de temperatura foram feitos no intervalo de $10{ }^{\circ} \mathrm{C}$ a $75^{\circ} \mathrm{C}$, com intervalos de 5 unidades, utilizando-se tampão Mcllvaine $\mathrm{pH}$ 5,0 (ácido cítrico 0,1 mM/fosfato de sódio $0,2 \mathrm{mM}$ ) mantendo-se as mesmas condiçôes do ensaio-padrão.

Os efeitos dos íons, agentes redutores e açúcares foram avaliados utilizando-se $200 \mu \mathrm{L}$ de soluçóes de $10 \mathrm{mM}$ de $\mathrm{MgCl}_{2}, \mathrm{CaCl}_{2}, \mathrm{KCl}, \mathrm{CuSO}, \mathrm{NaCl}$, -mercaptoetanol, lactose, $\mathrm{D}$-galactose, D-glicose, sacarose, rafinose, melibiose, ácido etilenodiaminotetraacético (EDTA). A solução contendo tampão, enzima e efetores foi incubada por 15 minutos a $37{ }^{\circ} \mathrm{C}$ e, em seguida, foi acrescentado o substrato e a reação conduzida, mantendo-se as mesmas condiçóes do ensaiopadrão.

As constantes de Michaelis-Menten $\mathrm{K}_{\mathrm{M}}$ e $\mathrm{V}_{\max }$ foram determinadas utilizando as concentraçóes finais de 0,032 ; 0,$064 ; 0,118 ; 0,192 ; 0,32 ; 0,64 ; 0,8,1,28 ; 1,6$ e $2,0 \mathrm{mM}$ 
de $\rho$-NPGAL. Os valores de $\mathrm{K}_{\mathrm{M}}$ e $\mathrm{V}_{\text {max }}$ foram calculados por meio da curva de velocidade, em funçấo da concentração de substrato, curva de Michaelis-Menten. Foi utilizado o programa Statistica versão 6 (StatSoft 2001).

O experimento foi montado no delineamento inteiramente ao acaso. Foram utilizadas três repetiçóes e a leitura da atividade foi feita em triplicatas. Os dados foram submetidos à análise de variância e à regressão. Os dados referentes aos efetores foram submetidos à análise de variância e ao teste de média. Nos casos em que não se encontrou modelo adequado para os dados, calculou-se o erro padrão da média para cada ponto. Todas as análises foram feitas a 5\% de significância.

\section{RESULTADOS E DISCUSSÃO}

A germinação das sementes de $D$. nigra apresentou aumento expressivo a partir do quinto dia de embebiçáo, chegando a $90 \%$ em nove dias (Figura 1). Borges e Borges (1996) encontraram 64\% de germinaçáo para a mesma espécie. Utilizando a mesma espécie, Andrade et al. (2006) encontraram $70 \%$ de germinação ao final de 30 dias de análise. Como as sementes do presente trabalho e de Borges e Borges (1996) tiveram a mesma procedência, debita-se à época de colheita a variação na viabilidade das sementes. Acrescente-se à procedência as variaçôes em relação à Andrade et al. (2006).

As atividades da enzima $\alpha$-galactosidase, no eixo embrionário e nos cotilédones, de sementes de $D$. nigra durante o período analisado podem ser observadas na Figura 2. Não se detectou presença da $\alpha$-galactosidase no eixo quando a semente estava seca. Ocorreu aumento acentuado na atividade da enzima no embriấo nos primeiros três dias, decrescendo a valores próximos daqueles dos cotilédones, que permaneceram baixos durante todo o tempo de avaliação. A atividade nos cotilédones aumentou no primeiro dia e praticamente estabilizou, sem maiores variaçôes, até o sétimo dia. Desta forma, a quantificação de atividade na avaliação de alteraçôes nas reservas de galactomanano ou extração da enzima, visando

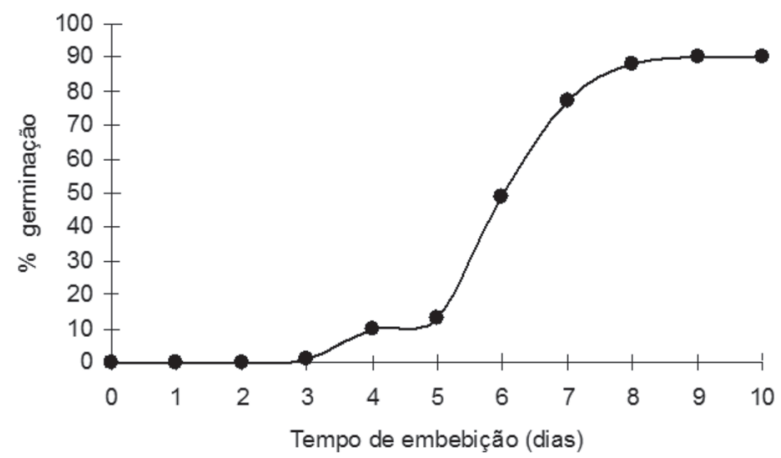

Figura 1 - Porcentagem de germinação cumulativa de sementes de Dalbergia nigra ao longo do tempo.

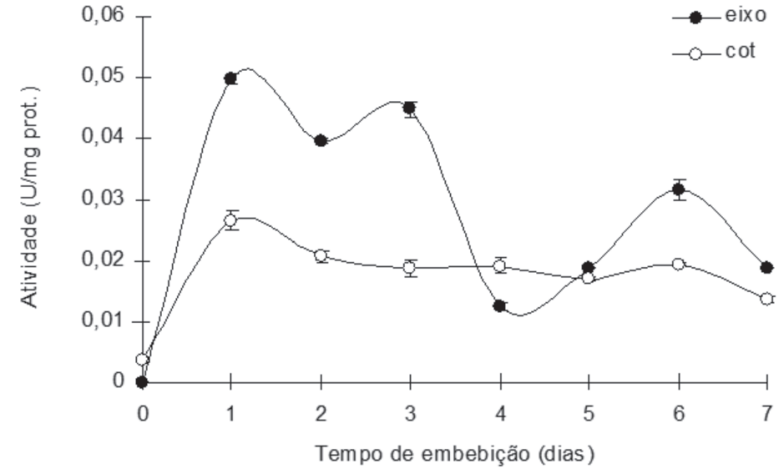

Figura 2 - Atividade específica de $\alpha$-galactosidase, no eixo embrionário e nos cotilédones, de sementes de Dalbergia nigra durante a germinação. As barras indicam 0 erro padrão.

seu aproveitamento industrial, deve ser feita no eixo nos primeiros três dias de germinação. Resultado semelhante ao encontrado neste trabalho foi obtido por Borges et al. (2004), em sementes de Platymiscium pubescens. Nos cotilédones de sementes de Caesalpinia peltophoroides náo foi detectada queda na atividade da $\alpha$-galactosidase durante o período analisado (Borges et al. 2005). Em sementes de Tachigali multijuga, a atividade máxima de $\alpha$-galactosidase foi detectada em 108 horas de embebição (Fialho 2007).

Observou-se que os teores de proteína presentes no eixo embrionário e nos cotilédones não diferiram significativamente ao longo do período analisado, porém houve diferença significativa entre o eixo e os cotilédones. Os teores no eixo embrionário foram de $3,54 \mathrm{mg} \mathrm{mL}^{-1}$ nas sementes secas e de $2,34 \mathrm{mg} \mathrm{mL}^{-1}$ em 24 horas de embebição, permanecendo decrescente até o terceiro dia e voltando a aumentar no quarto dia da análise. O teor de proteína nos cotilédones aumentou a partir do quinto dia de embebiçấo, alcançando valores maiores que os encontrados no eixo embrionário (Figura 3).

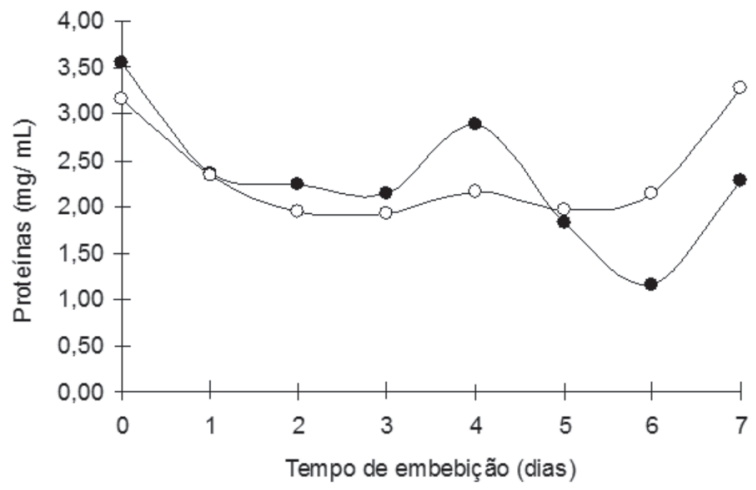

Figura 3 - Teor de proteína no eixo embrionário (•) e nos cotilédones (o) de sementes de Dalbergia nigra durante a germinação. 
A mobilização de reservas de proteínas em sementes está relacionada com o processo de desenvolvimento da plântula (Buckeridge et al. 2004). Assim, a partir da embebição, ocorrem hidrólise e mobilização destas reservas dos cotilédones para o eixo em desenvolvimento. No entanto, nos cotilédones de sementes de $D$. nigra, observa-se que está ocorrendo acúmulo destas reservas (Figura 3). Provavelmente, a proteína dos cotilédones não esteja sendo utilizada no eixo embrionário, pois aí o seu teor é suficiente para manter seu crescimento. Resultado semelhante foi observado em sementes de Apuleia leiocarpa e C. peltophoroides, em que os teores médios de proteínas no eixo embrionário não diferiram significativamente durante o período de embebição, enquanto nos cotilédones houve significativo acúmulo (Pontes et al. 2002; Borges et al. 2005). Em sementes de Erythrina velutina e de Euphorbia heterophylla, o conteúdo de proteína cotiledonar solúvel decresceu durante a germinaçáo e o crescimento da plântula (Oliveira et al. 1998; Suda e Giorgini 2000).

A Figura 4A mostra os resultados da atividade da enzima em relaçáo à variaçáo do $\mathrm{pH}$. Percebe-se que a faixa de maior atividade da enzima no eixo embrionário e nos cotilédones foi entre 5,0 e 6,0. A atividade no eixo embrionário foi significativamente maior que nos cotilédones. $\mathrm{O}$ eixo embrionário é a regiáo de intenso crescimento meristemático
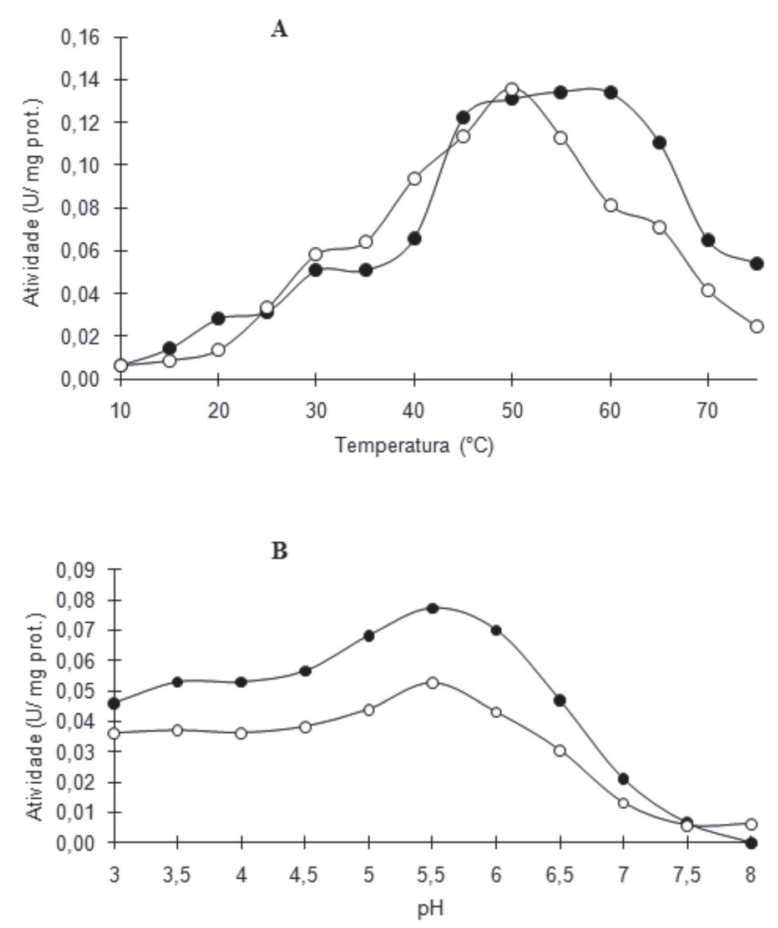

Figura 4 - Efeito do pH (A) e da temperatura (B) na atividade de $\alpha$-galactosidade no eixo embrionário (•) e nos cotilédones (o) de sementes de Dalbergia nigra. e, isso pode explicar a maior atividade da $\alpha$-galactosidase em relaçáo aos cotilédones. Em sementes de $P$. pubescens, as atividades máximas das enzimas do eixo embrionário e dos cotilédones estiveram na faixa de $\mathrm{pH}$ entre 4,5 e 6,0 (Borges et al. 2004). Guimarães et al. (2001) demonstraram que a faixa de $\mathrm{pH}$ de maior atividade da mesma enzima foi entre 5,0 e 5,5 em sementes de Glycine max, alcançando 6,0, conforme Viana (2002). Já em sementes de C. peltophoroides, o pH de maior atividade nos cotilédones foi na faixa de 4,0 a 5,0 e no eixo embrionário de 5,5 a 6,0 (Borges et al. 2005). Para a $\alpha$-galactosidase purificada, o $\mathrm{pH}$ de máxima atividade da enzima foi de 4,5 para uma fração e de 6,0 para a outra, em sementes de Castanea sativa (Dey 1981).

$\mathrm{O}$ aumento da temperatura resultou no aumento na atividade da $\alpha$-galactosidase até a temperatura de $50^{\circ} \mathrm{C}$ a $60^{\circ} \mathrm{C}$ para o eixo embrionário e de $50^{\circ} \mathrm{C}$ nos cotilédones (Figura 4B). Borges et al. (2004) observaram que com o aumento da temperatura houve aumento na atividade da $\alpha$-galactosidase do eixo embrionário de sementes de $P$. pubescens, com maior atividade em $55^{\circ} \mathrm{C}$, enquanto nos cotilédones a temperatura ficou na faixa de 50 a $55^{\circ} \mathrm{C}$. Viana (2002) e Guimaráes et al. (2001) obtiveram as maiores atividades para $\alpha$-galactosidase nas faixas de 45 a $50^{\circ} \mathrm{C} \mathrm{e} 40$ a $55^{\circ} \mathrm{C}$ para as sementes $G$. max , variedades Doko e CAC-1, respectivamente.

Os efeitos dos efetores na atividade da $\alpha$-galactosidase no eixo embrionário encontram-se na Figura 5A. A atividade da enzima foi inibida significativamente por $\beta$-mercaptoetanol e $\mathrm{CuSO}_{4}$ e, em menor extensão, por galactose, EDTA e rafinose. Glicose e sacarose estimularam a atividade da enzima, porém não apresentaram diferenças significativas entre si. Os sais de cloreto de cálcio, de potássio e de magnésio também tiveram efeito positivo na atividade, formando um grupo distinto. A lactose foi a responsável pela maior atividade da enzima. Nos cotilédones, a atividade da enzima foi inibida por $ß$-mercaptoetanol e $\mathrm{CuSO}_{4}$ (Figura 5B). Os demais efetores apresentaram atividade superior ao do substrato $\rho \mathrm{NP}-\alpha-\mathrm{Gal}$. A inibição da $\alpha$-galactosidase por íons, nos eixos embrionários e nos cotilédones, sugere reação que envolve grupos carboxílicos, ou grupo amino e imidazol da histidina no sítio ativo da enzima (Dey e Pridam 1972).

$\mathrm{O} \beta$-mercaptoetanol é um agente redutor que promove a redução das pontes de enxofre, formadas pelos grupamentos sulfidrilas de cisteínas, presentes na enzima, promovendo sua inibição. Deste modo os resultados sugerem que a alfagalactosidase de $D$. nigra apresenta grupos sulfidrilas que sáo essenciais à catálise. $\mathrm{O}$ íon $\mathrm{Cu}^{2+}$ é um conhecido inibidor irreversível de enzimas por reagir formando complexos com a mesma (Falkoski et al. 2006).

Atividade da $\alpha$-galactosidase em sementes de $C$. peltophoroides foi inibida por SDS, $\mathrm{CuSO}_{4}$, galactose e melibiose em ambos os compartimentos da semente (Borges 


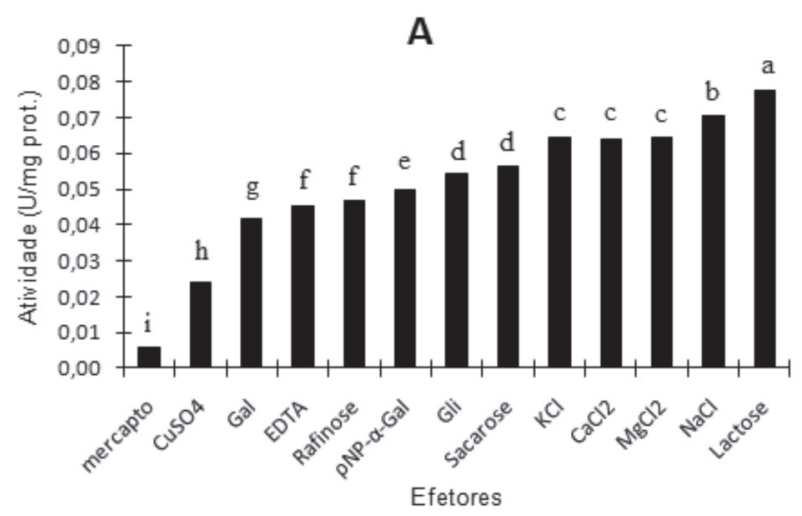

B

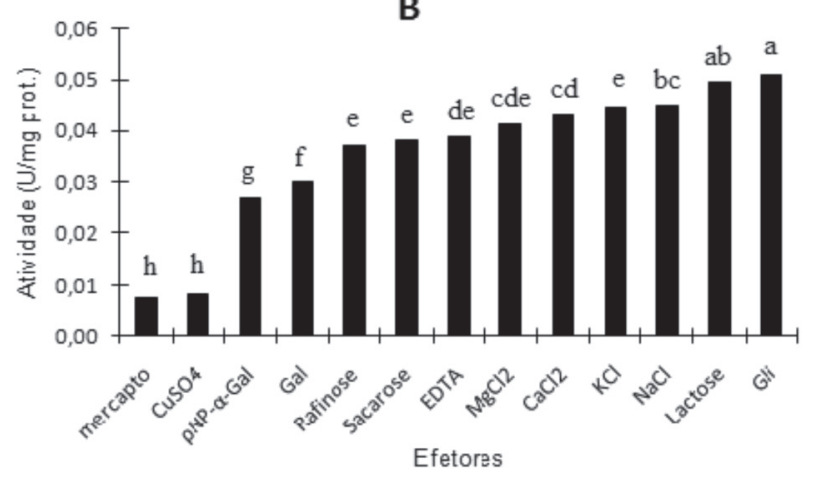

Figura 5 - Efetores da atividade de $\alpha$-galactosidade no eixo embrionário (A) e nos cotilédones (B) de sementes de Dalbergia nigra. Médias seguidas pela mesma letra nas colunas não diferem entre si pelo teste de média a $5 \%$ de significância. As barras referentes ao p-NPGal representam os ensaios controle realizados somente com a presença de substrato e sem efetores.

et al. 2005). O efeito dos efetores em sementes de P. pubescens foi distinto entre cotilédones e eixo embrionário (Borges et al. 2004). Segundo Oliveira et al. (2005), o cobre inibiu fortemente a atividade da $\alpha$-galactosidase C2 e totalmente da $\mathrm{C} 1$ em sementes de P. pubescens, bem como em sementes de Vicia sativa e de Prumus amygdalus (Dey e Pridham 1972).

Os valores de $\mathrm{K}_{\mathrm{M}} \mathrm{e} \mathrm{V}_{\mathrm{Max}}$ do eixo embrionário e cotilédones foram de $0,239 \mathrm{mM}$ e $0,228 \mathrm{mM}$, e 0,0053 e $0,0051 \mathrm{mM}$ $\min ^{-1}$, respectivamente. Em sementes de C. peltophoroides, os valores de $\mathrm{K}_{\mathrm{M}}$ para eixo e cotilédones foram 1,74 e 2,64 $\mathrm{mM}$, respectivamente. Segundo os autores, provavelmente são enzimas distintas (Borges et al. 2005). Os valores de $\mathrm{K}_{\mathrm{M}}$ encontrados para os compartimentos de sementes de D. nigra foram bem próximos, o que pode indicar que as enzimas sejam as mesmas, diferentemente do encontrado no trabalho com sementes de $C$. peltophoroides e $P$. pubescens em que os valores de $\mathrm{K}_{\mathrm{M}}$ foram diferentes entre o eixo e os cotilédones, indicando que as enzimas são distintas (Borges et al. 2004, 2005).

\section{CONCLUSÕES}

A $\alpha$-galactosidase está presente nos cotilédones de sementes secas; e no eixo embrionário, a enzima é detectada a partir da embebição.

A atividade específica da $\alpha$-galactosidase em sementes de $D$. nigra aumenta com o início da embebição, tanto nos cotilédones como no eixo embrionário.

A atividade da $\alpha$-galactosidase foi máxima na temperatura de 50 a $60{ }^{\circ} \mathrm{C}$ no eixo embrionário e $50{ }^{\circ} \mathrm{C}$ nos cotilédones.

$\mathrm{O}$ pH 5,5 foi o de máxima atividade para o eixo embrionário e os cotilédones.

$\mathrm{O} \mathrm{CuSO}_{4}$ e o $\beta$-mercaptoetanol inibiram a atividade da $\alpha$-galactosidase em ambos os compartimentos da semente.

\section{AGRADECIMENTOS}

À CAPES pela concessáo da bolsa.

\section{BIBLIOGRAFIA CITADA}

Andrade, A.C.S.; Pereira, T.S.; Fernandes, M.J.; Cruz, A.P.M.; Carvalho, A.S.R. 2006. Germination substrate, temperature and post-seminal development of Dalbergia nigra seeds. Pesquisa Agropecuária Brasileira, 41:517-523 (in Portuguese, with abstract in English).

Bom, I,; Wassenaar, V.D.; Boot, J. 1998. Hybrid affinity chromatography of $\alpha$-galactosidase from Verbascum thapsus $\mathrm{L}$. Journal of Chromatography, 808: 133-139.

Borges, E.E.L.; Borges, R.C.G. 1996. Phisiological changes of osmoconditioned seeds of Jacarandá-da-bahia (Dalbergia nigra (Vell.).Fr. All). Revista Árvore, 20: 147-154 (in Portuguese, with abstract in English).

Borges, E.E.L; Rezende, S.T.; Borges, R.C.G.; Perez, S.C.J.G.A. 2005. Alphagalactosidase characterization and its relationship with seed germination of Caesalpinia peltophoroides (Leguminosae Caesalpinioideae). Revista Árvore, 29: $525-533$ (in Portuguese, with abstract in English).

Borges, E.E.L; Rezende, S.T.; Borges, R.C.G.; Perez, S.C.J.G.A. 2004. Characterization of alpha-galactosidase in embryos and cotyledons of seed Platymiscium pubescens Micheli, Var. pubencens (tamboril-da-mata), Revista Brasileira de Sementes, 26: 82-90 (in Portuguese, with abstract in English).

Bradford, M.M. 1976. A rapid and sensitive method for the quantification of microgram quantities of proteins utilizing the principle of protein-dye binding. Analytical Biochemistry, 72: 248-254.

Buckeridge, M.S.; Santos, H.P.; Tiné, M.A.; Aidar, M.P.M. 2004. Mobilization of reserves, p. 163-185. In: Ferreira, A.G.; Borghetti, F. (Eds) Germination: from basic to applied. Editora Artmed, Porto Alegre, Rio Grande do Sul. 323p. (in Portuguese, with abstract in English).

Buckeridge, M.S.; Dietrich, S.M.C. 1996. Mobilization of the raffinose family oligosaccharides and galactomanannan in 
germinating seeds of Sesbania marginata Benth. (LeguminosaeFaboideae). Plant Science, 117: 33-43.

Chrost, B; Kolukisaogla, U; Schulz, B; Krupinska, K. 2007. An $\alpha$-galactosidase with na essential function during leaf development. Planta, 225: 311-320.

Dey, P.M. 1981. $\alpha$-galactosidase from sweet chestnut seeds. Phytochemistry, 20: 1493-1496.

Dey, P.M.; Pridham, J.B. 1972. Biochemistry of $\alpha$-galactosidases. Advances in Enzymology, 36: 91-130.

Edwards, M.; Scott, C.; Gidley, M.J.; Reid, J.S.G. 1992. Control of mannose/galactose ratio during galactomananna formation in developing legume seeds. Planta, 187: 67-74.

Falkoski, D.L.; Guimarães, V.M.; Callegari, C.M.; Reis, A.P.; Barros, E.G.; Rezende, S.T. 2006. Processing of Soybean Products by Semipurified Plant and Microbial $\alpha$-Galactosidases. Journal of Agricultural and Food Chemistry, 54: 10184-10190.

Fialho, L.S. 2007. Purification and characterization of an $\alpha$-galactosidase from seeds of Tachigali multijuga cloning and partial gene stachyose synthase from soybean. Dissertaçáo de mestrado, Universidade Federal de Viçosa, Viçosa, Minas Gerais. 140pp(in Portuguese, with abstract in English).

Fujimoto, Z.; Kaneko, S.; Monna, M.; Kobayashi, H.; Mizuno, H. 2003. Crystal structure of rice $\alpha$-galactosidase complexed with D-galactose. Journal of Biological Chemistry, 278: 20313-20318.

Guimarães, V.M.; Rezende, S.T.; Moreira, M.A.; Barros, E.G.; Felix. C.R. 2001. Characterization of $\alpha$-galactosidases from germinating soybean seed and their use for hydrolysis of oligosaccharides. Phytochemistry, 58: 67-73.

Kontos, F.; Spyropoulos, C.G. 1996. Seed coat inhibits the production of $\alpha$-galactosidase and endo- $\beta$-mananase in the endosperm of developing carob seed. Plant Physiology and Biochemistry, 34: 787-793.

Lahuta, L.; Gorecki, R.J.; Michalczyk, D.; Piotrowiczcieslak, A.L.C. 2000. Alpha-D-galactosidase activity in stored yellow lupin (Lupinus luteus L.) seeds. Electronic Journal Polish Agricultural Universities, 3: 1-10.

Lorenzi, H. 1992. Brazilian Trees: manual for identification and cultivation of native tree of Brazil. Nova Odessa: Plantarum. 352 pp. (in Portuguese, with abstract in English).
Marques, M.A.; Paula, R.C.; Rodrigues, T.J.D. 2002. Electrical conductivity test for the determination of the physiological seed quality of Dalbergia nigra (VELL.) Fr. All. ex Benth. Revista Brasileira de Sementes, 24: 271-278 (in Portuguese, with abstract in English).

Mcllvaine, T.C. 1921. A buffer solution for colorimetric comparison. Journal of Biological Chemistry, 49: 185-186.

Oliveira, M.V.; Mota, D.M.; Teixeira, C.R.; Cavada, B.S.; Moreira, R.A.; Vasconcelos, I.M. 1998. Protein and lectin mobilization during Erythrina velutina Aurantiaca seed germination and seedling growth in the dark. Revista Brasileira de Fisiologia Vegetal, 10: 25-30.

Oliveira, G.; Guimarães, V.M.; Borges, E.E.L.; Fialho, L.S.; Oliveira, M.G.A.; Rezende, S.T. 2005. Purificação e caracterização de $\alpha$-galactosidases de sementes de Platymiscium pubescens Micheli. Revista Árvore, 29(4): 535-543.

Pontes, A.C.; Borges, E.E.L.; Borges, R.C.G.; Soares, C.P.B. 2002. Seed reserve mobilization of Apuleia leiocarpa (Vogel) J.F. Macbr. (garapa) during imbibition. Revista Árvore, 26(5): 593-601 (in Portuguese, with abstract in English).

Saraswathy, N.; Sadasivam, S.; Subha, K.; Poorani, N. 2007. Purification and properties of alfa-galactosidase from whiterot fungus Pleurotus florida. Indian Journal Biochemistry Biophysical, 44(2): 76-81.

StatSoft, Inc. ,2001. Statistic (data analysis sot ware system), Version 6 (www. Stasolf.com).

Suda, C.N.K.; Giorgini, J.F. 2000. Seed reserve composition and mobilization during germination and initial seedling development of Euphorbia heterophylla. Revista Brasileira de Fisiologia Vegetal, 12(3): 226-245.

Viana, S.F. 2002. Characterization of $\alpha$-galactosidase for hydrolysis of soy oligosaccharides raffinose. Dissertação de mestrado, Universidade Federal de Viçosa, Viçosa, Minas Gerais. 64 pp (in Portuguese, with abstract in English).

Recebido em 16/07/2010

Aceito em 21/10/2010 